\title{
Correlation between Intelligence Quotient and the Level of
}

\section{Improvement of Autistic Children}

\author{
Nawaf Mohammed Al-Sabaawi * Dr. Elham Khattab Al-Jammas **
}

\begin{abstract}
Background and Aims: Autism in children is known to affect brain systems implicated in cognitive, communication, social functioning and intelligence. Although autism is a neurobiological disorder, behavioral interventions are currently the primary treatments for individuals with autism. The objective of the present study was to identify the correlation between intelligent quotient and the level of improvement of autistic children.
\end{abstract}

Materials and Methods: A descriptive design was carried out in the rehabilitation clinic for children with autism at psychiatric research unit-Mosul Medical College / University of Mosul. Data were collected by using Childhood Autism Rating scale (CARS) and I.Q was measured by Stanford-Binet scale in order to achieve the objectives of the present study. A pre-test was carried out on children with autism who participated in the rehabilitation program. The childhood autism rating scale was used for this purpose. After five months, post-test was administered for autistic children to identify the effects of caregivers' techniques and interventions on the children with autism disorders. The subjects of the study were consisted of the 30 children who were received interventions at the rehabilitation clinic for autistic children. Data were analyzed by using SPSS version 20.

Results: The study revealed that most autistic children who participated in the study had learning disabilities and low moderate intelligence quotient, they accounted $33.3 \%$ and $27.7 \%$, respectively. The study confirmed that the children's I.Q had highly significant difference regarding improvement.

Conclusion: The study concluded that there was significant difference in intelligence quotient between pre and post intervention levels of autism (improvement).

Keywords: Autism, Intelligence Quotient, Interventions, Improvement.

\section{INTRODUCTION}

Autism is a developmental disability significantly affecting verbal and non-verbal communication and social interactions, generally evident before age three that adversely affects the child's educational performance. Other characteristics often associated with autism are engagement in repetitive activities and stereotyped movements, resistance to environmental change or change in routine and unusual responses to sensory experiences. Etiology remains unclear. Autism is a disorder marked by severe intellectual social and emotional impairment. Children with autism demonstrate poor response to sensory stimuli, not recognizing their parents, and may lack interest in their environment (Ludwig and Harstall, 2001).

World Health Organization defined autism spectrum disorders (ASDs), as a spectrum of psychological conditions characterized by widespread abnormalities of social interactions and communication, as well as severely restricted interests and highly repetitive behavior (WHO, 2006). Autism is a chronic developmental disorder characterized by impairments in the areas of social interaction, communication, and repetitive behavior. Early detection followed by early intervention is likely to provide the best chance of long-term beneficial outcome for those children with autism (Zhang et al., 2006). Autism is a disorder of markedly abnormal or impaired development in social interactions and communication occurring in early childhood (Keltner et al., 2011).

There are five main subtypes of autistic spectrum disorder (ASD): classical autism, Asperger's syndrome, Rett's disorder, childhood degenerative disorder and pervasive developmental disorder (not otherwise specified). Classic autism and Asperger syndrome are the most commonly diagnosed, but are differentially classified in the IDC-10 and DSM-IV publications (WHO, 2006; APA, 2004).

* MSc in Nursing / Assist. Lecturer Candidate / College of Nursing / University of Mosul / nawaf.mohammed99@yahoo.com

** Professor / College of Medicine / University of Mosul. 
The triad of impairments associated with autism has been useful for teachers when identifying the educational support needs of individual pupils with autism (Jones, 2009).

The number of reported cases of autism increased dramatically in the (1990) and early (2000). This increase is largely attributable to changes in diagnostic practices, referral patterns, availability of services, age at diagnosis, and public awareness (Fombonne, 2009). The generally accepted prevalence rate for autism spectrum disorders has been 4-5 in every 10000 births. However, recent estimates suggest a rate of about 1 in 500 when a broader spectrum of disorders is included. There is a higher prevalence among males. The ratio varies depending on the definition, but studies reveal a male-to-female ratio between 4:1 to 5:1 (Kim and Sandra, 2003).

For now, there is no cure for Autism. There are, however, highly effective treatment, rehabilitation and intervention methods available that can help individuals and their families address the characteristics of this disorder. Early interventions based on best practices are intended to help children with autism to develop skills, learn to communicate effectively, share in family life and enjoy success at school (John, 2012).

Early intervention for children with autism is most effective and provides the best possible outcomes for children when provided as early as possible after diagnosis. Early intervention services provide the family with the knowledge; skills and support to meet the needs of child optimize child's development and increase their ability to participate in family and community life (Beeston and Smith, 2012).The reason and purpose behind this study was to identify the correlation between intelligent quotient and the level of improvement of autistic children.

\section{MATERIALS AND METHODS}

In order to achieve the objective of the present study a descriptive study was carried out from 1st. December, 2012 through June 30th,
2013. The subjects of the study were consisted of 30 autistic children who were received interventions at the rehabilitation clinic for autistic children. Data were collected by using Childhood Autism Rating scale (CARS) (Schopler, 1988) throughout interview technique for parents of children and I.Q was measured by Stanford-Binet scale.

\section{Criteria for selection of the subjects in this study were:}

1. The children who were diagnosed with Autism in Psychiatric Research Unit.

2. The children who were involved in the rehabilitation program.

3. Their age ranges between $\left(2 \frac{6}{12}-12\right)$ years.

4. Their family agreed to let him/her participate in the study.

\section{RESULTS}

Table (1): Frequency and percentage of children's I.Q based on Stanford-Binet scale:

\begin{tabular}{|l|c|c|}
\hline \multicolumn{1}{|c|}{ Intelligence quotient test } & F & \% \\
\hline Mentally Retarded $(\leq 67)$ & 2 & 6.7 \\
\hline Learning disabilities $(68-78)$ & 10 & 33.3 \\
\hline $\begin{array}{l}\text { Low moderate intelligence quotient (79- } \\
88)\end{array}$ & 8 & 27.7 \\
\hline Moderate intelligence quotient (89-110) & 4 & 13.3 \\
\hline $\begin{array}{l}\text { High moderate intelligence quotient (111- } \\
120)\end{array}$ & 2 & 6.7 \\
\hline Excellent intelligence quotient (121-131) & 3 & 10.0 \\
\hline Very Excellent intelligence quotient $(\geq 131)$ & 1 & 3.3 \\
\hline Total & 30 & 100 \\
\hline
\end{tabular}

Table (2): Distribution of children (pre and post interventions) according to Childhood Autism Rating Scale (CARS).

\begin{tabular}{|l|c|c|c|c|}
\hline \multirow{2}{*}{$\begin{array}{c}\text { Childhood autism } \\
\text { rating scale Grading }\end{array}$} & \multicolumn{2}{c|}{$\begin{array}{c}\text { Pre- } \\
\text { interventions }\end{array}$} & \multicolumn{2}{c|}{$\begin{array}{c}\text { Post- } \\
\text { interventions }\end{array}$} \\
\cline { 2 - 5 } & No. & \% & No. & \% \\
\hline No Autism & 0 & 0.0 & 9 & 30.0 \\
\hline Mild to moderate Autism & 24 & 80.0 & 17 & 56.7 \\
\hline Sever Autism & 6 & 20.0 & 4 & 13.3 \\
\hline Total & 30 & 100 & 30 & 100 \\
\hline
\end{tabular}

Table (3): Analysis of variance for the difference between children's I.Q, and the post intervention levels of autism (outcomes).

\begin{tabular}{|c|c|c|c|c|c|c|}
\hline Topics & Source of variance & Sum of Squares & D.f & Mean Square & F & Sig. \\
\hline \multirow{2}{*}{$\begin{array}{c}\text { Intelligence } \\
\text { Quotient }\end{array}$} & Between Groups & 23.425 & 2 & 11.713 & \multirow{3}{*}{6.597} & \multirow{2}{*}{0.005} \\
\cline { 2 - 5 } & Within Groups & 47.941 & 27 & 1.776 & \\
\cline { 2 - 5 } & Total & 71.367 & 29 & & & HS \\
\hline
\end{tabular}

\section{DISCUSSION}

The current study findings revealed that the highest percentage of children's intelligence quotient is between $68-78$ according to Stanford-
Binet scale, they accounted about $33.3 \%$. The study also revealed that the percentage of mentally retarded children is $6.7 \%$, this result is different from Eric and Suniti study (Eric and 
Suniti, 2001), who reported that autism is associated with mental retardation in $70 \%$ of cases. The reason of this difference probably related to the samples of the study and type of scale.

The results showed that most children with autism (Pre-interventions) had mild to moderate autistic features $80 \%$. The result revealed that the percentage of autistic children who were improved was $30 \%$, this result was in contradiction to a study conducted by Freeman and Perry (2010) on autistic children in the Toronto Preschool autism Service (Freeman and Perry, 2010), which revealed that the percentage of autistic children who improved were $44 \%$. This difference might reflect the type and facilities available for the intervention program.

Relative to the relationship between these children's intelligence quotient and the improvement, the results of the present study confirmed that the children's I.Q had highly significant difference regarding improvement $(\mathrm{p} \leq 0.01)$.

The DSM-IV defines the diagnosis of mental retardation as the combination of sub average intellectual functioning (IQ $<70$ ) and concurrent deficits in adaptive functioning. Autistic individuals have poorer adaptive function than would be predicted by IQ alone (Filipek et al., 2000)

\section{CONCLUSIONS}

The current study concludes that there is an improvement among autistic children according to autism rating scale; the level of improvement was $(30 \%)$. The children's improvement in total childhood autism scale scores was clearly apparent from intake to discharge and decreasing from about 38.80 to 30.63 , on average. The current study also concluded that there was significant difference in intelligence quotient between pre and post intervention levels of autism (improvement).

\section{RECOMMENDATIONS}

The study recommends that Staff of the Rehabilitation program must be knowledgeable and skilled in the autism field and provision enough staff to rehabilitate autistic children. The study also recommends that children with autism should be eligible for special education services within the category of autistic spectrum disorders.

\section{REFERENCE}

American Psychiatric Association (APA). (2004). Diagnostic and Statistical Manual of Mental Disorders. ( $4^{\text {th }}$ ed.). Text Revision (DSM-IVTR). Washington, DC: American Psychiatric Publishing.
Beeston, P., and Smith, A. (2012). My child has autism: information for Queensland families of young children. The State of Queensland (Department of Communities, Child Safety and Disability Services. p13.

Eric, F., and Suniti, Ch. (2001). No evidence for a new variant of MMR-induced autism. Pediatrics. 108(4). p1-8

Freeman, N., and Perry, A. (2010). Outcomes of Intensive Behavioral Intervention in the Toronto Preschool Autism Service. Journal on Developmental Disabilities. 16(2).p19-24

Filipek, P., Accardo, P., and Baranek, G. (2000). The screening and diagnosis of autistic spectrum disorders. J Autism Dev Disord. 29. p 439-484.

Fombonne, E. (2009). Epidemiology of pervasive developmental disorders. Pediatr Res. 56(6). p 591-598.

John, S. (2012). A parents handbook your guide to autism program. Ministry of Children and family Development. British Colombia. p 5

Jones, G., English, A., Guldberg, K., Jordan, R., Richardson, P., and Waltz, M. (2009). Educational Provision for Children and Young People on the Autism Spectrum Living in England: a Review of Current Practice, Issues and Challenges. Summary Report 2 for Professionals and Providers Retrieved from: http://www.a utism educationtrust.org.uk On January 2013

Keltner, L., Bostrom, E., and McGuinness, M. (2011). Psychiatric Nursing. (6 ${ }^{\text {th }}$ ed.). Elsevier Mosb. p 509-510 .

Kim, W., and Sandra, M. (2003). Teaching Students with Autism Spectrum Disorders. Alberta Learning, Alberta, Canada. p 8-19

Ludwig, S., and Harstall, C. (2001). Intensive Intervention Programs for Children with Autism. Alberta T5J 3S4 . p 1-2.

Schopler, E., Reichler, R. J., and Renner, B.R. (1988). The Childhood Autism Rating Scale (CARS). Los Angeles: Western Psychological Services.

World Health Organization.(2006). International Statistical Classification of Diseases and Related Health Problems. $10^{\text {th }}$ ed.(ICD-10).

Zhang, J., Wheeler, J., and Richey, D. (2006). Cultural Validity in Assessment Instruments for Children with Autism from a Chinese Cultural Perspective, International Journal of Special Education. 21(1). p109-120. 